\title{
Family pedigrees of children with suspected childhood apraxia of speech
}

\author{
Barbara A. Lewis ${ }^{\text {a,* }}$, Lisa A. Freebairn ${ }^{\text {a }}$, Amy Hansen ${ }^{\text {a }}$, \\ H. Gerry Taylor ${ }^{\mathrm{a}}$, Sudha Iyengar ${ }^{\mathrm{b}}$, Lawrence D. Shriberg ${ }^{\mathrm{c}}$ \\ ${ }^{\mathrm{a}}$ Department of Pediatrics, Rainbow Babies and Childrens Hospital, School of Medicine, \\ Case Western Reserve University, Cleveland, $\mathrm{OH}, \mathrm{USA}$ \\ ${ }^{\mathrm{b}}$ Department of Epidemiology and Biostatistics, Case Western Reserve University, \\ Cleveland, $\mathrm{OH}, \mathrm{USA}$ \\ ${ }^{\mathrm{c}}$ Waisman Center, University of Wisconsin, Madison, WI, USA
}

Received 18 April 2003; received in revised form 23 July 2003; accepted 13 August 2003

\begin{abstract}
Forty-two children (29 boys and 13 girls), ages 3-10 years, were referred from the caseloads of clinical speech-language pathologists for suspected childhood apraxia of speech (CAS). According to results from tests of speech and oral motor skills, 22 children met criteria for CAS, including a severely limited consonant and vowel repertoire, difficulty sequencing syllables, and inconsistent and unusual errors. Family pedigrees for these children were constructed through parent interviews and direct testing of nuclear family members. Familial aggregation for speech-sound and language disorders was demonstrated with $86 \%$ reporting at least one nuclear family member affected. Based on parent report, 13 of the 22 children $(59 \%)$ had at least one affected parent. However, CAS was evident in only two siblings of probands with CAS and two probands with other speech-sound disorders. Based on testing, overall affection rates of speech-sound/language disorders were higher in families of children with CAS than in families of children with other speech-sound disorders. Mothers of children with CAS demonstrated a higher affection rate than mothers of children with other speech-sound disorders. A sex-related threshold model of transmission was also supported with brothers more often affected than sisters for male probands only. If our inclusionary criteria for CAS are valid, these findings support a general verbal trait deficit hypothesis.

Learning outcomes: (1) As a result of this activity, the participant will understand potential familial risk factors for CAS; (2) will differentiate aggregation for speech-sound and language disorders in families with CAS from families of children who have other speech-sound disorders; (3) will

\footnotetext{
* Corresponding author. Present address: Behavioral Pediatrics and Psychology 6038, Rainbow Babies and Childrens Hospital, Case Western Reserve University, 11100 Euclid Ave., Cleveland, OH 44106-6038, USA. Tel.: +1-216-844-6204; fax: +1-216-844-6276.

E-mail address: bx1@po.cwru.edu (B.A. Lewis).
} 
distinguish how familial aggregation differs in families of boys and girls with CAS; (4) will determine how children with CAS differ in severity from those with other speech-sound disorders. (C) 2003 Elsevier Inc. All rights reserved.

Keywords: Childhood apraxia of speech (CAS); Genetic; Speech-sound disorder; Language disorder; Pedigree

Childhood apraxia of speech (CAS) has been regarded as a highly heritable condition with strong family aggregation. Morley (1965) found that $67 \%$ of the individuals with CAS in her sample had a family member with speech and/or language disorders. Two studies of single large pedigrees of individuals with CAS also found that about half of the individuals in their samples had family members who were affected with speech disorders (Fisher, Vargha-Khadem, Watkins, Monaco, \& Pembrey, 1998; Saleeby, Hadjian, Martinkosky, \& Swift, 1978). In one of the few group studies in this area, Thoonen, Maassen, Gabreels, Schreuder, and de Swart (1997) reported that 6 out of 11 children with CAS had a family history of speech and language disorders. These investigators and others (Aram \& Glasson, 1979; Aram \& Nation, 1982; Crary, 1993; Hall, Jordan, \& Robin, 1993) have suggested an autosomal dominant mode of transmission of the disorder, with inter-individual differences in subject phenotypic characteristics (variable phenotypic expression of the disorder for individuals with the genotype).

New evidence for the familial aggregation and transmission of CAS was observed in one of the two large pedigrees cited above, known as the K.E. family, with over half its members reported having a speech-sound disorder (Fisher et al., 1998; Vargha-Khadem, Watkins, Alcock, Fletcher, \& Passingham, 1995). The original report of the K.E. family described the affected family members as presenting with developmental apraxia of speech (Hurst, Baraitser, Auger, Graham, \& Norell, 1990). Subsequent studies reported other deficits in phonological processing and expression, syntax, nonlinguistic oral praxis, and performance IQ (Watkins, Dronkers, \& Vargha-Khadem, 2002). Upon further testing, the primary impairment in affected family members appeared to be the ability to sequence oral movements, a hallmark characteristic of CAS (Watkins et al., 2002). Genetic studies of the K.E. family revealed mutations in a gene located at chromosome 7q31, called the FOXP2 gene (Lai, Fisher, Hurst, Vargha-Khadem, \& Monaco, 2001). The FOXP2 gene codes for a transcription factor and is expressed in the brain. Neuroimaging of family members indicated abnormalities in regions of the frontal lobe and associated motor systems. In particular, the superior portion of the caudate nucleus showed reduced volume bilaterally upon MRI analysis (Watkins et al., 2002). This was the first study that provided direct evidence for a single gene with a corresponding neurological abnormality that is associated with CAS. However, it is not known whether the K.E. family is representative of families with CAS in the general population.

\section{Limitations of previous studies}

Unfortunately, past studies of familial aggregation in CAS have been limited in several respects. First, investigations have focused mainly on single pedigrees or small samples of 
identified individuals and their families. A second limitation is that there has been little agreement on diagnostic criteria for CAS. Several authors have presented lists of distinguishing characteristics of CAS of potential utility in diagnosis (Hall et al., 1993; Ozanne, 1997; Shriberg, Aram, \& Kwiatkowski, 1997a, 1997b; Stackhouse, 1992). However, children with CAS seldom present with all of these characteristics. The most commonly reported characteristics are difficulties sequencing phonemes and syllables, trial and error groping behaviors, and inconsistency in articulation with unusual error forms on both consonants and vowels (Hall et al., 1993; Stackhouse, 1992; Velleman \& Strand, 1994).

Identification of affected family members presents a further methodological challenge. Typically, biological family members of children with CAS, although not diagnosed with CAS, demonstrate rates of speech-sound, language, reading, and other verbal learning disorders that are higher than those found in the general population. These findings support a common etiology and justify the use of a broad phenotype for CAS diagnosis. Once a case with CAS has been identified, any family member with a speech-sound, language, reading, and/or verbal learning disorder may be classified as affected. In contrast, a narrower definition of the CAS phenotype would consider family members to be affected if they demonstrated or reported a history of CAS. Using this narrower definition presumes that CAS is a specific form of speech-sound/language disorder, with a genetic etiology that is distinct from that of other speech/language disorders.

Previous studies of the family histories of children with CAS have not included a comparison group of families of children with other speech-sound and language disorders. Hence, we do not know relative rates of speech-sound disorders in these other types of families. There is, nevertheless, considerable evidence that speech-sound and language disorders aggregate within families (Felsenfeld, McGue, \& Broen, 1995; Gopnik \& Crago, 1991; Lahey \& Edwards, 1995; Lewis, 1992; Neils \& Aram, 1986; Rice, Haney, \& Wexler, 1998; Shriberg \& Kwiatkowski, 1994; Spitz, Tallal, Flax, \& Benasich, 1997; Tallal, Ross, $\&$ Curtiss, 1989; Tomblin, 1989). Findings from these studies indicate that $23-40 \%$ of firstdegree family members of individuals with speech-sound/language disorders are affected. Findings from twin and adoption studies also suggest a genetic component to speech and language (Bishop, North, \& Donlan, 1995; Felsenfeld \& Plomin, 1997; Lewis \& Thompson, 1992; Tomblin \& Buckwalter, 1998).

Previous studies have also failed to account for gender differences in the prevalence of CAS. Most studies report a higher prevalence of CAS in males than in females. Hall et al. (1993) report that 170 of 229 cases of CAS reported in the literature (74\%) have been males. Although research shows that more males than females have other forms of speech and language impairments, the ratio of males to females is considerably lower for these other disorders. Studies indicate point prevalence rates for speech delay of $4.5 \%$ for boys and $3.1 \%$ for girls (Shriberg, Tomblin, \& McSweeny, 1999). The sex difference in prevalence estimates may reflect bias in clinical ascertainment of cases in studies of CAS, in contrast to the population-based cluster-sampling procedures used in the Shriberg et al. (1999) study. A method for reducing this potential sex bias is to examine affection status among siblings of the cases. Because siblings are not selected through clinical referral, sex ratios among the siblings of probands may more accurately reflect sex differences in rates of affection for a disorder (DeFries, 1989). 


\section{Rationale for the present study}

The present study examines pedigrees of many children with CAS rather than the pedigree of a single family. Children with CAS were identified by multiple criteria within a narrow age range thus minimizing the effects of intervention and/or development or manifestation of the speech-sound disorder. For the purposes of this study, the term "speech-sound disorder" will be employed, as phonological processing errors were not distinguished from articulation errors in ascertaining the sample. The term "language disorder" is employed rather than specific language impairment (SLI) as no attempt was made to distinguish a specific deficit in language from other cognitive delays. Affection status of family members was determined through direct testing as well as historical reports. A somewhat narrower phenotype than that of previous reports was utilized, with family members being classified as affected only if they reported a history of a speech-sound and/or language disorder. Individuals with only reading or spelling disorders were not considered affected. Even though these disorders are often comorbid with speech-sound disorders, they are defined according to different criteria. Comparison groups of families of children with speech-sound disorders other than CAS were included and sex differences were examined.

Four research questions were addressed:

1. Do speech-sound and/or language disorders aggregate in families of children with CAS? Based on prior reports, we predicted that the rates of these disorders among nuclear family members of children with CAS would be higher than that in the general population.

2. Does the aggregation for speech-sound and/or language disorders in families of children with CAS differ from aggregation observed in families of children who have other speech-sound disorders? If other speech-sound disorders show different rates or patterns of familial aggregation, then underlying genetic mechanisms may differ. Higher rates of affection may suggest a higher genetic loading (i.e., more risk genes) within a family. Given previous findings, we predicted that the affection rates in families of children with CAS would be higher than those of families of children with other speech-sound disorders.

3. Do male probands with CAS differ from female probands in familial aggregation for speech-sound and for language disorders? A sex-specific threshold model was explored by comparing (a) rates of affected nuclear family members for male versus female probands and (b) rates of affected brothers versus sisters for male and female probands. Based on evidence that a higher genetic loading for the disorder may need to be present for the disorder to be manifested in females (i.e., lower penetrance of the genotype), we predicted that families of female probands would show higher affection rates than families of male probands. A higher penetrance in males means that a lower genetic loading is needed in families for manifestation of the phenotype, which in turn will tend to increase the differences between sex prevalence rates. For this reason, we also predicted that the brother:sister ratio of affection status would be greater for male probands than for female probands.

4. Do children with CAS differ from those with other speech-sound disorders in profiles or severity of speech-sound and language disorders? Based on prior reports, we 
predicted that children with CAS would perform more poorly than children with other speech-sound disorders on measures of articulation, language, oral motor skills, and syllable sequencing.

\section{Method}

Candidate participants for this study were tested individually in two sessions to reduce potential effects of fatigue on test results. Testing was carried out in a speech research laboratory at Case Western Reserve University's Department of Pediatrics or, at the parent's request, in a quiet and adequately lit room in the family's home. All speech-sound productions were tape recorded using a Sony Professional Tape Recorder (WM-DC6) and an Audio-Technica Omnidirectional Microphone (AT-804). Responses were recorded initially on-line using broad phonetic transcription. Speech-sound samples were later transcribed in broad transcription.

\subsection{Participants}

Participants were recruited from the clinical caseloads of community speech/language pathologists. All of the children were between the ages of 3 years 0 months through 10 years 11 months and were required to demonstrate a speech-sound disorder of unknown causality. Thus, the criterion for participation included: (1) normal hearing acuity as defined by passing a pure tone audiometric screening test at $25 \mathrm{dBHL}$ ISO for 500, 1000, 2000, and $4000 \mathrm{~Hz}$ bilaterally and fewer than six reported episodes of otitis media prior to age 3 as reported by the parent; (2) absence of a history of neurological disorders other than CAS such as cerebral palsy, as reported by the parent; and (3) normal intelligence defined as a Performance IQ (PIQ) of 80 or above on the Wechsler Intelligence Scale for Children-Third Edition (WISC-III; Wechsler, 1991) or the Wechsler Preschool and Primary Scale of Intelligence Test-Revised (WPPSI-R, Wechsler, 1989).

\subsubsection{Probands with CAS}

A multi-step process was employed to identify children who met strict criteria for CAS. Initial selection was based on a clinical diagnosis of suspected CAS by the child's speech-language pathologist. Forty-two children were referred with suspected CAS. The children were then screened for a speech production disorder involving deficits in the motor programming aspects of speech. Only participants showing a severely restricted phonemic repertoire, including errors of sound class, place and manner of production, voicing, and vowel errors met screening criteria for the diagnosis. Evidence for restriction in phonemic production included a score below the fifth percentile on the Goldman-Fristoe Test of Articulation (GFTA; Goldman \& Fristoe, 1986), the presence of at least three phonological processing errors in the moderate to severe range, and an overall rating of 4 (severe) on the Khan-Lewis Phonological Analysis (KLPA; Khan \& Lewis, 1986). Screening eliminated 11 children from the sample, including all of the 9 children over 6 years of age and 2 of the younger children. The children eliminated 
may have met screening criteria at a younger age or may have had a milder form of CAS.

Eligibility for the diagnosis also required reduced diadochokinetic rates as defined by a Total Function Score (TFS) of at least 2 S.D. below the mean for age on the Oral Speech Motor Control Protocol (Robbins \& Klee, 1987) and difficulty with sequencing sounds and syllables. Sequencing errors were noted for each child on the repetition of multisyllabic real and nonsense words or in the imitation of syllable sequences, such as pataka on the Oral Speech Motor Control Protocol. Due to the paucity of multisyllabic productions in children with apraxia, sequencing errors are often difficult to identify in younger children. Therefore, phonetic transcripts of the multisyllabic real and nonsense words were examined for sequencing errors. This criterion, which was applied to document problems in programming of sequential articulatory movements, eliminated seven additional children who did not demonstrate sequencing errors.

A final diagnostic criterion required that the participants demonstrate unusual error types, defined as nondevelopmental processes, metathetic errors, prolongations, and addition errors in their connected speech samples. Three children failed to satisfy this inclusionary criterion, leaving 22 who met all criteria for CAS, including 16 boys and 6 girls, ages 3-6 years $($ mean $=4.9$; S.D. $=0.91)$.

\subsubsection{Probands with speech-sound disorders}

The comparison group of children with speech-sound disorders was 93 children recruited from the clinical caseloads of speech-language pathologists working at community speech and hearing centers or in private practice in the greater Cleveland area. Children excluded from the CAS sample were not considered eligible. Findings on a subset of this group $(n=28$, speech-sound disorder without language impairment; $n=24$, speech-sound disorder with language impairment) were previously reported (Lewis, Freebairn, \& Taylor, 2000). All children presented with normal hearing, the absence of a neurological diagnosis, and WISC-III or WPPSI-R PIQ $\geq 80$.

Participants in the comparison group also met two additional criteria. They had a moderate to severe expressive speech-sound disorder as defined by (a) a score of 1 S.D. or greater below the mean on the Goldman-Fristoe Test of Articulation-Sounds in Words Subtest (GFTA; Goldman \& Fristoe, 1986) prior to enrollment in speech-language therapy, and (b) commission of at least three phonological error types as identified by the KhanLewis Phonological Analysis (Khan \& Lewis, 1986). Additionally, the Oral and Speech Motor Control Protocol (Robbins \& Klee, 1987) confirmed a normal peripheral speech mechanism.

Comparison children were assigned to one of two groups based on preschool language status: speech-sound disorder in isolation ( $\mathrm{S}$ group) or speech-sound disorder with additional language impairment (SL group). The criteria for language impairment, consistent with Tomblin et al. (1997), included a scaled score of less than 8 on two or more subtests of the Test of Language Development-Primary (TOLD-P:2; Newcomer \& Hammill, 1988). As shown in Table 1, the three groups (CAS, S, and SL) did not differ significantly in age, gender, or distribution of socioeconomic status as rated on the Hollingshead Four Factor Index of Social Class (Hollingshead, 1975). 
Table 1

Sample demographics characteristics

\begin{tabular}{lccc}
\hline Characteristic & CAS group $(n=22)$ & S group $(n=51)$ & SL group $(n=42)$ \\
\hline Age in years & & & $4.9(0.7)$ \\
$\quad$ Mean (S.D.) & $4.9(0.9)$ & $5.6(1.5)$ & $3.8-6.1$ \\
Range & $3.8-6.4$ & $3.9-6.4$ & $28 / 14$ \\
Male/female & $16 / 6$ & $29 / 22$ & \\
SES (Hollingshead) & & & $4(10 \%)$ \\
1 & $1(5 \%)$ & 0 & $4(10 \%)$ \\
2 & $2(9 \%)$ & $5(10 \%)$ & $13(31 \%)$ \\
3 & $6(27 \%)$ & $7(14 \%)$ & $11(26 \%)$ \\
4 & $10(45 \%)$ & $21(41 \%)$ & $10(23 \%)$ \\
5 & $3(14 \%)$ & $18(35 \%)$ & \\
\hline
\end{tabular}

Note. CAS: childhood apraxia of speech, S: speech-sound disorders without language disorder, SL: speechsound disorder with language disorder.

\subsection{Phenotyping nuclear family members}

Affection status of nuclear family members in the CAS and comparison groups was determined both through historical report and by directly testing family members when possible. Only data on biological parents and full siblings are presented. Affection status for siblings under 3 years of age was not determined. Following the procedures described by Lewis and Freebairn (1993), all parents were interviewed for family history of speech and language disorders. Family members were classified as affected for a speech-sound disorder and/or language disorder if they had ever been enrolled in therapy for a persistent moderate to severe speech-sound disorder and/or language disorder. Reliable information on the specific type of speech and language problem could not always be obtained from the informants. Efforts were made to secure school records but detailed therapy records were not available. Affection status was obtained by retrospective methods, with reliance on self-reports and descriptions by family members. Determination of affection status in this way is a standard procedure in studies of family pedigrees and broadly classifies family members as affected or generally unaffected based on report of one or both caregivers. It also allows for the identification of family members as affected whose speech-sound and language problems may have resolved either through therapy or with age.

The informant was also questioned about whether or not family members had a history of reading, spelling or learning difficulties. Information on these comorbid conditions is presented in Appendix B. For the purposes of this study, children and parents were considered non-affected if they presented with or had histories of reading, spelling or learning difficulties, but did not have a history of a speech-sound and/or language disorder.

Further phenotyping of nuclear family members was accomplished through direct testing of siblings who were 4 years of age or older (CAS group, $n=27$; $\mathrm{S}$ group, $n=80$, SL group, $n=63$ ) and all parents who agreed to testing (CAS group, $n=20 ; \mathrm{S}$ group, $n=42$; SL group, $n=34$ ). Siblings who were $4-7$ years of age were considered to have a speech-sound disorder if they met the same criteria outlined above for the probands. Older siblings and parents were considered to have speech-sound difficulties if they were 
unable to repeat more than $25 \%$ of the multisyllabic or nonsense words correctly. Siblings and parents were considered to have a language disorder if they scored 1 S.D. or greater below the mean on two or more subscales of the TOLD-P:2 or the Clinical Evaluation of Language Fundamentals-Revised (CELF-R; Semel, Wiig, \& Secord, 1987).

Comparisons of affection status based on historical report to affection status based on direct testing revealed the following. For the sibling groups, affection status for speechsound disorders based on historical reports was in agreement with the affection status based on direct testing in $77 \%$ of cases in the CAS group, $66 \%$ of cases in the S group, and $81 \%$ of cases in the SL group. Affection status of siblings for language disorders based on historical reports was in agreement with test results in $92 \%$ of cases for the CAS group, $86 \%$ for the S group, and $89 \%$ for the SL group. In the parent groups, affection status for speech-sound disorders based on historical reports matched the affection status based on direct testing in $84 \%$ of cases for the CAS group, in $74 \%$ of cases for the S group, and in $65 \%$ of cases for the SL group. Historical reports of language disorders in the parent groups was in agreement with test results in $78 \%$ of cases for the CAS group, $95 \%$ of cases for the $\mathrm{S}$ group, and $88 \%$ of cases for the SL group. Differences in affection status between historical reports and direct testing may be due to remediation of the earlier problem, compensatory strategies employed by the individual, and/or the insensitivity of tests to subtle speech/language disorders (e.g., due to ceiling effects of the tests employed).

\subsection{Measures}

Assessment procedures included parent interviews to obtain data on developmental history, as well as formal testing of children's speech-sound development, oral motor skills, language skills, and prosody. Questions about the children's development included inquiries regarding the age at which they spoke their first words and sentences. Inquiry was also made regarding problems in motor development, medical/neurological history, and progress in speech therapy.

Probands in all three groups (CAS, S, and SL) received all the measures in a counter balanced manner. The Goldman-Fristoe Test of Articulation-Sounds in Words subtest (GFTA; Goldman \& Fristoe, 1986) was administered to assess speech-sound production in initial, medial, and final word positions, as well as consonant blends. Responses were transcribed on-line as well as audiotape recorded for later review. Transcriptions of $10 \%$ of the samples by a second speech-language pathologist indicated that the transcriptions were highly reliable (95\% point-to-point agreement). A Khan-Lewis Phonological Process Analysis (KLPA; Khan \& Lewis, 1986) was performed on responses from the GFTA. Data from the KLPA used in data analysis included the age-adjusted percentile score severity rating and instances of non-developmental phonological processes and syllable errors.

Speech-sound development was further quantified using the Percentage of Consonants Correct (PCC) metric (Shriberg, Austin, Lewis, McSweeny, \& Wilson, 1997). A 12\% reliability estimate based on approximately 100 speech samples obtained for this project yielded average point-to-point interjudge agreement values of $85 \%$ for narrow transcription of consonants and $91 \%$ for broad transcription of consonants.

Samples were also coded for inconsistent, metathetic or sequencing errors, and prosodic disturbances. Two licensed and certified master's level speech-language pathologists 
independently reviewed the converstional speech samples. The presence or absence of metathetic errors, inconsistent errors, and sequencing errors was noted for each participant.

The Multisyllabic Word Task (Catts, 1986) was administered to assess syllable sequencing and increases in errors with increasing task demands. In this task, participants were asked to repeat 20 multisyllabic words presented by audiotape. The responses were audiotaped, phonetically transcribed, and analyzed for phonological processes and syllable structure. The percent of phonemes correctly produced was entered into data analysis.

The Oral and Speech Motor Control Protocol (Robbins \& Klee, 1987) assessed oral structures and motor functions. The Oral and Speech Motor Protocol was standardized on 90 children without speech or language impairments ages 2:6-6:11. The test consists of 24 observations of the vocal tract structures and their relationships and 56 observations of vocal tract functioning. Function tasks are rated on a 3-point scale and 2 points are awarded for a correct response, 1 point for an emerging response, and 0 for an incorrect response. In addition rates of repetitions of monosyllables and polysyllables are recorded. The test yields a Total Structure Score and a Total Function Score. The Total Structure Score was employed to ensure a normal peripheral speech mechanism. The Total Function Score was employed to assess the participant's rate and accuracy in syllable sequencing. $Z$ scores were obtained employing age-adjusted normative standards.

The Test of Language Development-Primary 2nd Edition (TOLD-P:2; Newcomer \& Hammill, 1988) was used to measure overall language abilities. The subtests administered were Picture Vocabulary, Relational Vocabulary, Oral Vocabulary, Grammatic Understanding, Sentence Imitation, and Grammatic Completion.

\subsection{Procedures}

\subsubsection{Analyses}

Chi-square tests were employed to examine group differences in familial aggregation. Family-wise adjustments were not made, nor were Bonferroni corrections due to the small sample size. Affection rates for family members of children with CAS were compared to those for family members of children in the S and SL groups. Affection rates of family members of male and female probands within each group were also compared. Analysis of covariance (ANCOVA) was used to compare groups in the domains of speech-sound development, language, and oral/motor skills. Age was employed as a covariate in these analyses.

\section{Results}

\subsection{Characteristics of CAS sample}

All but 6 of the 22 children (73\%) showed delays in acquisition of their first words (defined as a failure to produce words by 1 year of age). These same 16 children were also delayed in acquisition of first sentences (defined as a failure to combine two words prior to 2 years of age). Ten children (45\%) reported having had motor delays other than in oral motor skills (e.g., delays in crawling, walking). Four children (18\%) were described by a 
neurologist as presenting with soft neurological signs. The parents of 19 children (86\%) reported that their children had made slow progress in speech-language therapy.

All children presented with severe speech-sound disorders and oral motor sequencing difficulties as evidenced by their performance on the GFTA, KLPA, and TFS. Four children also scored below the mean on the TSS, demonstrating some type of oral structure abnormality. These abnormalities were primarily dental and did not compromise the functioning of the speech mechanism. All but 5 of the 22 children $(77 \%)$ demonstrated better receptive than expressive language skills, however, half of the children presented with delays in both receptive and expressive language.

Analysis of a conversational speech sample revealed metathetic errors in 21 children (91\%), groping behaviors in 14 children (64\%), and increased errors on polysyllabic words in 21 children $(91 \%)$. Percentage of consonants correct scores ranged from 57 to $93 \%$, with a mean of $72 \%$ (S.D. $=12.1$ ).

\subsection{Pedigree analyses}

Table 2 presents affection rates in the nuclear families of children in the CAS, S, and SL groups. Rates are presented by sex of the proband and for males and females combined. The findings indicate familial aggregation of speech-sound and language disorders in all three groups. Based on historical report, at least one first-degree family member was affected for speech-sound and/or language disorders in 19 of the $22(86 \%)$ children with CAS, with over half $(13 / 22,59 \%)$ of these probands having at least one affected parent. Test defined affection status were also high for the CAS group. Rates of affection for all nuclear family members in all groups were well above population estimates of $6 \%$ (cf. Shriberg et al., 1999).

Based on historical report, the affection rate was higher in male probands with CAS than those with other speech-sound disorders and based on testing, affection rates were higher in the CAS group male probands, female probands, and combined probands. The difference

Table 2

Affection status of nuclear family members for speech-language disorders

\begin{tabular}{lcccc}
\hline Probands & $\begin{array}{l}\text { CAS group } \\
(n=22)\end{array}$ & $\begin{array}{l}\text { S group } \\
(n=51)\end{array}$ & $\begin{array}{l}\text { SL group } \\
(n=42)\end{array}$ & $\begin{array}{l}\text { Between-group } \\
\text { comparisons }\end{array}$ \\
\cline { 3 - 6 } & & & & $\chi^{2}$ \\
\hline
\end{tabular}

Note. CAS: childhood apraxia of speech, S: speech-sound disorders without language disorder, SL: speechsound disorder with language disorder. 
in affection rates (based on historical reports) for male but not female probands cannot be accounted for by differences between male and female probands in numbers of brothers and sisters, as chi-square analyses failed to reveal differences in this regard (brothers, $\chi^{2}=0.84, P=0.63$; for sisters, $\chi^{2}=1.32, P=0.52$ ).

Within-group analyses were then carried out to explore affection rates for male versus female probands. Based on historical report, affection rates were higher for female probands than male probands in the $S$ group $\left(\chi^{2}=10.6, P<0.001\right)$. Analyses of the CAS and SL groups failed to reveal differences in affection rates according to the sex of the proband (for the CAS group, $\chi^{2}=0.49, P=0.48$; and for the SL group, $\chi^{2}=0.65$, $P=0.42$ ). However, for male probands, brothers were more frequently affected than sisters in all three groups (for the CAS group, $\chi^{2}=6.0$, d.f. $=1, P=0.014$; for the SL group, $\chi^{2}=20.4$, d.f. $=4, P<0.001$; and for the $\mathrm{S}$ group, $\chi^{2}=7.9$, d.f. $=2, P=0.019$ ). Affection rates for brothers versus sisters did not differ for female probands.

Affection rates for speech-sound and language disorders for individual family members are presented in Table 3. Based on historical reports, affection rates were higher for mothers of children with CAS than for mothers of children in the S and SL groups. Based on testing, group differences were found for mothers, brothers, sisters, and total members.

Pedigrees of the children with CAS were further classified as representing vertical transmission (i.e., parent to child) of the speech-sound and/or language disorder if one or both parents were affected signaling a possible autosomal dominant pattern of inheritance. Vertical transmission may imply either Mendelian transmission or a polygenic transmission. Regardless of how we defined affection status, comparison of families with vertical transmission of disorders to families with nonvertical transmission failed to reveal differences in rates of affected family members.

Table 3

Affection status of nuclear family members for speech-language disorders by type of family member

\begin{tabular}{|c|c|c|c|c|c|}
\hline $\begin{array}{l}\text { Family } \\
\text { member }\end{array}$ & $\begin{array}{l}\text { CAS group } \\
(n=22)\end{array}$ & $\begin{array}{l}S \text { group } \\
(n=51)\end{array}$ & $\begin{array}{l}\text { SL group } \\
(n=42)\end{array}$ & $\chi^{2}$ & $P$ \\
\hline \multicolumn{6}{|c|}{ Affection status defined by historical report } \\
\hline Mother & $9 / 22(41 \%)$ & $7 / 51(14 \%)$ & $8 / 42(19 \%)$ & 6.93 & $0.031^{*}$ \\
\hline Father & $6 / 22(27 \%)$ & $14 / 51(27 \%)$ & $11 / 41(27 \%)$ & 0.01 & 0.996 \\
\hline Sisters & $6 / 14(43 \%)$ & $13 / 38(34 \%)$ & $11 / 42(26 \%)$ & 3.53 & 0.739 \\
\hline Brothers & $11 / 17(65 \%)$ & $30 / 59(51 \%)$ & $23 / 40(58 \%)$ & 9.78 & 0.460 \\
\hline Any of above & $30 / 75(40 \%)$ & $64 / 199(32 \%)$ & $53 / 165(32 \%)$ & 5.39 & 0.249 \\
\hline \multicolumn{6}{|c|}{ Affection status defined by testing } \\
\hline Mother & $5 / 11(45 \%)$ & $3 / 24(13 \%)$ & $4 / 21(19 \%)$ & 6.30 & $0.043^{*}$ \\
\hline Father & $4 / 9(44 \%)$ & $3 / 18(17 \%)$ & $4 / 13(31 \%)$ & 2.43 & 0.297 \\
\hline Sisters & $8 / 11(73 \%)$ & $10 / 34(29 \%)$ & $7 / 33(21 \%)$ & 10.25 & $0.006^{*}$ \\
\hline Brothers & $9 / 16(56 \%)$ & $10 / 46(22 \%)$ & $11 / 30(37 \%)$ & 6.77 & $0.034^{*}$ \\
\hline Any of above & $26 / 47(55 \%)$ & $26 / 122(21 \%)$ & $26 / 97(27 \%)$ & 19.40 & $<0.001^{* *}$ \\
\hline
\end{tabular}

Note. CAS: childhood apraxia of speech, S: speech-sound disorders without language disorder, SL: speechsound disorder with language disorder.

*Significant at 0.05 probability level.

** Significant at 0.001 probability level. 
Table 4

Group comparisons of test performance

\begin{tabular}{|c|c|c|c|c|c|c|c|}
\hline Measure & & $\begin{array}{l}\text { CAS group } \\
(n=22)\end{array}$ & $\begin{array}{l}\mathrm{S} \text { group } \\
(n=51)\end{array}$ & $\begin{array}{l}\text { SL group } \\
(n=42)\end{array}$ & $F$ & $P$ & $\mathrm{Eta}^{2}$ \\
\hline Goldman-Fristoe $^{\mathrm{a}, \mathrm{b}}$ & Mean (SD) & $1.7(1.0)$ & $26.3(17.5)$ & $21.8(21.4)$ & 15.8 & $<0.001$ & 0.297 \\
\hline Percentile score & Range & $<1-4.0$ & $2.0-78.0$ & $1.0-49.0$ & & & \\
\hline Khan-Lewis ${ }^{\mathrm{a}, \mathrm{b}}$ & Mean (SD) & $2.6(3.2)$ & $25.2(22.2)$ & $19.3(20.6)$ & 10.1 & $<0.001$ & 0.206 \\
\hline Percentile score & Range & $<1-15.0$ & $1.0-88.0$ & $1.0-50.0$ & & & \\
\hline TOLD total ${ }^{\mathrm{c}, \mathrm{d}}$ & Mean (SD) & $78.6(8.8)$ & $106.2(12.2)$ & $85.6(10.9)$ & 52.7 & $<0.001$ & 0.592 \\
\hline Standard score & Range & $67-95$ & $88-131$ & $61-96$ & & & \\
\hline TOLD listening ${ }^{\mathrm{c}, \mathrm{d}}$ & Mean (SD) & $91.2(14.4)$ & $108.7(12.0)$ & $93.5(11.4)$ & 20.0 & $<0.001$ & 0.262 \\
\hline Standard score & Range & $71-118$ & $88-136$ & $70-102$ & & & \\
\hline TOLD speaking ${ }^{\mathrm{c}, \mathrm{d}}$ & Mean (SD) & $71.3(11.0)$ & $99.0(16.4)$ & $80.5(11.1)$ & 15.5 & $<0.001$ & 0.562 \\
\hline Standard score & Range & $49-82$ & $79-128$ & $61-94$ & & & \\
\hline Total function ${ }^{\mathrm{a}, \mathrm{b}}$ & Mean (SD) & $-12.1(6.3)$ & $-1.6(2.9)$ & $-3.6(4.1)$ & 45.8 & $<0.001$ & 0.522 \\
\hline$Z$ score & Range & -23 to -2.0 & -10.1 to 2.6 & -13.4 to 2.6 & & & \\
\hline Multisyllabic words ${ }^{\mathrm{a}, \mathrm{b}}$ & Mean (SD) & $3.5(13.1)$ & $32.1(19.1)$ & $24.0(17.6)$ & 19.4 & $<0.001$ & 0.431 \\
\hline Percent correct & Range & $0-10$ & $0-60$ & $0-60$ & & & \\
\hline Percent Consonants & Mean (SD) & $72.4(12.1)$ & $88.1(7.4)$ & $83.9(8.3)$ & 16.5 & $<0.001$ & 0.483 \\
\hline Correct $^{\mathrm{a}, \mathrm{b}}$ & Range & $56.7-92.9$ & $72.4-96.7$ & $63.2-96.7$ & & & \\
\hline
\end{tabular}

Note. CAS: childhood apraxia of speech, S: speech-sound disorders without language disorder, SL: speechsound disorder with language disorder. TOLD: Test of Language Development-Primary 2.

${ }^{a} S$ group significantly different from CAS group by Tukey post hoc testing.

${ }^{\mathrm{b}}$ SL group significantly different from CAS group by Tukey post hoc testing.

${ }^{\mathrm{c}} \mathrm{S}$ group significantly different from SL group by Tukey post hoc testing.

\subsection{Comparisons of children with CAS and children with speech-sound disorders}

As shown in Table 4, children with CAS differed significantly from children in the $\mathrm{S}$ and SL groups on measures of articulation, language, and oral motor functions. As expected given the selection criteria, the S and SL groups differed on total, receptive, and expressive language measures. These groups did not differ on measures of articulation or oral motor skills. The mean ages in years at which the child's first words were spoken were 1.8 $($ S.D. $=0.8), 1.2$ (S.D. = 0.6), and 1.7 (S.D. = 0.8), for the CAS, S, and SL groups, respectively. The respective mean ages at which sentences were first spoken were 2.8 (S.D. $=0.9), 1.8$ (S.D. $=0.7)$, and 2.4 (S.D. $=0.9$ ).

\section{Discussion}

\subsection{Familial aggregation of CAS}

The findings of this study support a strong familial aggregation of speech-sound and language disorders within families of children with CAS. The percent of children with CAS 
with a positive family history (86\%) is at the high end of the range reported previously for children with speech-language disorders (28-75\%; Aram \& Glasson, 1979; Ferry, Hall, \& Hicks, 1975; Horwitz, 1984; Lewis, 1990; Lewis, Ekelman, \& Aram, 1989; Milloy \& Summers, 1989; Morley, 1957; Riley, 1984; Shriberg \& Kwiatkowski, 1994). This high affection rate may reflect the more stringent criteria we employed in identifying children with CAS.

The low rate of CAS among family members of children with CAS offers support for a verbal trait deficit hypothesis. A continuum of disorders was observed among the siblings of the CAS probands, ranging from mild articulation disorders to more severe speechsound disorders and language disorders.

\subsection{Comparison of familial aggregation in children with CAS versus children in the $S$ and SL groups}

If traits underlying CAS are polygenic, the same genes may contribute to both CAS and other speech-sound disorders, with families of children with CAS having a higher genetic loading than family members of children with milder speech-sound disorders. To test this hypothesis, we compared the familial aggregation in the CAS group to that in the S and SL groups. Although affection rates among nuclear family members were higher for children with CAS than for children in the S and SL groups, these differences were significant when affection status was based on testing but not when affection status was based on historical report. Based on historical report, rates of affected mothers were significantly higher for the CAS than the S or SL groups, but fathers were equally affected across all three groups $(27 \%)$. Affection rates for brothers were higher then those for other family members, but dissimilar across groups (51-65\%). Based on testing, affection rates were higher in the CAS group than in the other two groups for mothers, brothers, sisters, and total.

These findings fail to provide strong support for a unique etiology for CAS, as the same types of speech and language disorders were observed among families of each of the three proband groups. In our view, the most parsimonious interpretation of these findings is that families of children with CAS possess more risk genes for a verbal trait disorder. Another possible interpretation is that our criteria for CAS failed to discriminate it from other types of speech-sound disorders.

Discrepancies between rates of affection based on history versus testing may be due to the fact that only about half of the parents and $87 \%$ of the siblings were tested. In addition, affection status based on history classifies an individual as affected if, as a child, he/she presented with a clinically diagnosed speech-sound/language disorder. In contrast, direct testing only assesses an individual's present skills, but may provide a more sensitive and objective measure of affection status. Measures used to assess skills at an older age, such as repetition of multisyllabic real and nonsense words may tap different linguistic skills than traditional articulation and language tests.

\subsection{Other group comparisons}

Findings indicating that children with CAS presented with a more severe speech-sound and language disorder than participants in S or SL groups also support the hypothesis of a 
continuum of impairment in a common verbal trait. Children with CAS differed significantly from those in the S and SL groups in articulatory skills as measured by standard articulation tests (GFTA) and analysis of speech samples (PCC), as well as in speech-sound sequencing abilities as measured by the TFS and the repetition of multisyllabic word lists. Significant differences in receptive and expressive language skills were also observed between the CAS and S groups, but not between the CAS and SL groups. The latter finding suggests that, whereas children with CAS often present with language disorders, language impairment alone is not a good diagnostic marker for CAS. All but three of our children with CAS scored 1 S.D. or more below the mean on the expressive subscale of the TOLD$\mathrm{P}: 2$, and more than half of these participants scored 1 S.D. or more below the mean on the receptive subscale. Some authors have expressed the view that CAS is not limited to the articulatory and motor aspects of speech, but encompasses other aspects of language as well (Aram \& Glasson, 1979; Aram \& Nation, 1982; Crary, 1982). The presence of a variety of language-learning disorders among the probands and their families is consistent with this view.

\subsection{Sex differences in $C A S$}

With respect to sex differences in CAS, boys in our sample outnumbered girls by a ratio of more than 2:1. This ratio is slightly smaller than that reported by Hall et al. (1993). These researchers, however, suggested that the high ratio of males to females reflected referral bias. They speculated that equal numbers of males and females are found in populations of children with more severe symptoms of CAS. Given that our sample was drawn from clinical referrals, our findings are also subject to this referral bias. Nevertheless, we used stringent criteria to define CAS and the present sample likely represents the more severe end of the CAS spectrum. Our findings thus suggest that a higher prevalence of CAS among males may be representative of this disorder.

Sex differences in prevalence are frequently explained in terms of X-linked patterns of inheritance. Because a son inherits the X chromosome only from his mother, transmission from father to son is not observed in X-linked traits (Plomin, DeFries, McClearn, \& Rutter, 1997). X-linkage was therefore not supported by our results, as CAS was equally likely to be transmitted from mother to son as from father to son.

An alternative explanation for the sex differences in rates of CAS and other speech-sound disorders is that there is a sex-specific threshold (Carter, 1969, 1973; DeFries, 1989). As a higher genetic loading is required for manifestation of the phenotype in females, they should not only have lower rates of disorders, but also more affected family members than male probands. Further, as indicated earlier (see introduction), the brother:sister ratio for affected relatives of male probands should be higher than that for female probands. In support of these predictions, affection rates based on historical report were higher among brothers than sisters for male probands, but not for female probands (i.e., a lower threshold associated with a higher ratio of male:female family members affected). Further support for a sex-specific threshold model was provided by a higher overall affection rate for female probands than for male probands, but only for the $\mathrm{S}$ group. Our sample size, however, was small for investigating sex differences; hence additional studies employing a larger number of female probands will be needed to assess the level of support for this model. 


\section{Methodological limitations}

Several methodological limitations should be noted. First, the selection criteria for CAS eliminated older and less severely affected children. The use of these strict criteria also precluded examination of developmental variations in phenotypes of CAS. Children with mild symptoms of CAS may differ from those with more severe disorders in patterns of familial aggregation. More generally, the stringent criteria that we used to define CAS may be challenged. Methods such as acoustical analyses to support the diagnosis of CAS were not undertaken. An additional limitation includes our reliance on historical reports to establish affection status in many of our family members, especially among parents. Although tests that are sensitive to residual speech and language disorders in adults are lacking and testing could fail to detect previously resolved problems, direct testing of speech and language skills in parents may have revealed some disorders that were denied in historical reports. Finally, pedigree analysis alone cannot distinguish environmental from genetic influences, nor can it identify specific patterns of transmission. Molecular genetic studies are currently underway to better specify potential genetic bases for CAS.

In summary, the results of this study demonstrated that speech-sound and language disorders aggregate in families of children with CAS. Although affection rates in families of children with CAS were somewhat higher than those in families of children with other speech-sound disorders affection rates were elevated relative to population levels in all three groups. Furthermore, family members of all groups had similar types of speech/language problems. These findings challenge the view that CAS has an etiology that is distinct from that underlying other speech-sound disorders, and are thus consistent with the hypothesis that CAS and other developmental speech-sound disorders reflect a general verbal trait deficit. The high rate of affected mothers in the CAS group also supports a sex-specific threshold model. Further research is needed to discern whether or not speech-sound disorders fall along a continuum, with CAS representing the more severe end of the spectrum.

\section{Acknowledgements}

This research was supported by the National Institutes of Health, National Institute on Deafness and Other Communication Disorders, Grant DC00528 and NIH-NIDCD 1 RO3 DC004005. We wish to express our appreciation to the speech/language pathologists who assisted us in recruiting subjects, and to the families who generously agreed to participate.

\section{Appendix A. Continuing education}

1. Past studies of familial aggregation of CAS have been limited for several reasons. These include all of the following except

a. Identification of affected family members is challenging

b. There has been little agreement on the diagnostic criteria for CAS

c. CAS doesn't really exist

d. Investigation have focused mainly on small samples or single pedigrees 
2. Diagnostic criterion required for CAS in this study included

a. Restricted phonemic repertoire, reduced diadochokinetic rates, and deficits in motor programming

b. Low vocabulary skills, poor receptive language, and reduced MLU

c. Poor narrative abilities, low reading comprehension scores and sloppy handwriting

d. Poor word attack skills, inability to interpret multiple meanings, and lower spelling scores

3. In this study, affection status of nuclear family members in the CAS and comparison groups was determined through the use of

a. Acoustical analysis of the speech of family members

b. Historical report and by directly testing family members when possible

c. Reviewing videotapes and audiotapes of family celebrations and events

d. Securing school records of all the grandparents, aunts, and uncles

4. Some of the tests used for assessing the CAS, S, and SL groups in this study included all of the following except

a. Goldman Fristoe and Khan Lewis Phonological Analysis

b. Speech Sampling with Percentage of Consonants Correct

c. Multisyllabic Word Task

d. Woodcock Reading Mastery Test

5. The findings of this study suggest

a. There is a strong familial aggregation of speech-sound and language disorders within the families of children with CAS

b. There is a weak familial aggregation of speech-sound and language disorders with families of children with CAS

c. There is a unique, and unusual etiology for CAS

d. There is no risk of CAS when other family members present a history of speech or language difficulties

Appendix B. Comorbid conditions of nuclear family members

\begin{tabular}{lllll}
\hline $\begin{array}{l}\text { Family } \\
\text { member }\end{array}$ & Reading & Spelling & Stuttering & $\begin{array}{l}\text { Learning } \\
\text { disability }\end{array}$ \\
\hline $\begin{array}{l}\text { Mothers } \\
\text { CAS }\end{array}$ & $3 / 22(13.6 \%)$ & $3 / 22(13.6 \%)$ & $0 / 22$ & $3 / 22(13.6 \%)$ \\
S & $6 / 51(11.7 \%)$ & $5 / 51(9.8 \%)$ & $0 / 51$ & $0 / 51$ \\
SL & $3 / 42(7.1 \%)$ & $2 / 42(4.8 \%)$ & $1 / 42(2.4 \%)$ & $2 / 42(4.8 \%)$ \\
Chi-square $(P)$ & $0.82(0.662)$ & $1.57(0.455)$ & $1.75(0.416)$ & $\left(0.031^{*}\right)$ \\
Fathers & & & & \\
CAS & $5 / 22(22.7 \%)$ & $4 / 22(18.1 \%)$ & $2 / 22(9.1 \%)$ & $2 / 22(9.1 \%)$ \\
S & $3 / 51(5.9 \%)$ & $5 / 51(9.8 \%)$ & $1 / 51(2.0 \%)$ & $2 / 51(3.9 \%)$ \\
SL & $5 / 41(12.2 \%)$ & $5 / 41(12.2 \%)$ & $0 / 41$ & $4 / 41(9.8 \%)$ \\
Chi-square $(P)$ & $4.36(0.113)$ & $1.00(0.606)$ & $4.78(0.091)$ & $(0.505)$
\end{tabular}


Appendix B (Continued)

\begin{tabular}{lllll}
\hline $\begin{array}{l}\text { Family } \\
\text { member }\end{array}$ & Reading & Spelling & Stuttering & $\begin{array}{l}\text { Learning } \\
\text { disability }\end{array}$ \\
\hline Sisters & & & & \\
$\quad$ CAS & $4 / 14(28.6 \%)$ & $0 / 14$ & $0 / 14$ & $1 / 14(7.1 \%)$ \\
S & $6 / 38(15.8 \%)$ & $3 / 38(7.9 \%)$ & $0 / 38$ & $2 / 38(5.3 \%)$ \\
SL & $4 / 36(11.1 \%)$ & $5 / 36(13.9 \%)$ & $4 / 36(11.1 \%)$ & $1 / 36(2.8 \%)$ \\
Chi-square $(P)$ & $2.298(0.317)$ & $2.468(0.291)$ & $6.053\left(0.048^{*}\right)$ & $0.522(0.770)$ \\
Brothers & & & & \\
CAS & $5 / 17(29.4 \%)$ & $4 / 17(23.5 \%)$ & $2 / 17(11.8 \%)$ & $3 / 17(17.6 \%)$ \\
S & $9 / 56(16.1 \%)$ & $5 / 56(8.9 \%)$ & $1 / 56(1.8 \%)$ & $3 / 56(5.4 \%)$ \\
SL & $9 / 40(22.5 \%)$ & $7 / 40(17.5 \%)$ & $1 / 40(2.5 \%)$ & $4 / 40(10 \%)$ \\
Chi-square $(P)$ & $1.607(0.448)$ & $2.856(0.240)$ & $3.999(0.135)$ & $2.543(0.280)$ \\
Any member & & & & \\
CAS & $17 / 75(22.7 \%)$ & $11 / 75(14.7 \%)$ & $4 / 75(5.3 \%)$ & $9 / 75(12 \%)$ \\
S & $24 / 196(12.2 \%)$ & $18 / 196(9.2 \%)$ & $2 / 196(1.0 \%)$ & $7 / 196(3.6 \%)$ \\
$\quad$ SL & $21 / 159(13.2 \%)$ & $19 / 159(11.9 \%)$ & $6 / 159(3.8 \%)$ & $11 / 159(6.9 \%)$ \\
Chi-square $(P)$ & $5.07(0.079)$ & $1.80(0.406)$ & $4.62(0.099)$ & $6.72(0.034 *)$ \\
\hline
\end{tabular}

\section{References}

Aram, D. M., \& Glasson, C. (1979). Developmental apraxia of speech. Paper presented at the Annual Convention of the American Speech-Language-Hearing Association Meeting, Los Angeles, CA.

Aram, D. M., \& Nation, J. E. (1982). Child language disorders (pp. 144-249). St. Louis: C.V. Mosby.

Bishop, D. V. M., North, T., \& Donlan, C. (1995). Genetic basis of specific language impairment: evidence from a twin study. Developmental Medicine and Child Neurology, 37, 56-71.

Carter, C. O. (1969). Genetics of common disorders. British Medical Bulletin, 25, 52-57.

Carter, C. O. (1973). Multifactorial genetic disease. In V. A. McKusick \& R. Clairborne (Eds.), Medical genetics (pp. 199-208). New York: HP Publishing.

Catts, H. W. (1986). Speech production/phonological deficits in reading disordered children. Journal of Learning Disabilities, 19, 504-508.

Crary, M. A. (1982). Developmental verbal dyspraxia: A phonological perspective. Miniseminar presented at the annual meeting of the American Speech and Hearing Association, Toronto.

Crary, M. A. (1993). Developmental motor speech disorders. San Diego, CA.: Singular Publishing Group.

DeFries, J. (1989). Gender ratios in children with reading disability and their affected relatives: A commentary. Journal of Learning Disability, 22, 544-555.

Felsenfeld, S., McGue, M., \& Broen, P. A. (1995). Familial aggregation of phonological disorders: Results from a 28 year follow-up. Journal of Speech and Hearing Research, 38, 1091-1107.

Felsenfeld, S., \& Plomin, R. (1997). Epidemiological and offspring analyses of developmental speech disorders using data from the Colorado Adoption Project. Journal of Speech and Hearing Research, 40, 778-791.

Ferry, P. C., Hall, S. M., \& Hicks, J. L. (1975). Dilapidated speech: Developmental verbal dyspraxia. Developmental Medicine and Child Neurology, 17, 749-756.

Fisher, S. E., Vargha-Khadem, F., Watkins, K. E., Monaco, A. P., \& Pembrey, M. E. (1998). Localisation of a gene implicated in a severe speech and language disorder. Nature, 18, 168-170.

Goldman, R., \& Fristoe, M. (1986). The Goldman-Fristoe Test of Articulation. Circle Pines, MN: American Guidance Service. 
Gopnik, M., \& Crago, M. B. (1991). Familial aggregation of a developmental language disorder. Cognition, 39, $1-50$.

Hall, P. K., Jordan, L. S., \& Robin, D. A. (1993). Developmental dyspraxia of speech: Theory and clinical practice. Austin, TX: Pro-Ed.

Hollingshead, A. B. (1975). Four factor index of social class. Unpublished manuscript, available from A. B. Hollingshead, Department of Sociology, Yale University, New Haven, CT 06520.

Horwitz, S. J. (1984). Neurological findings in developmental verbal apraxia. In W. H. Perkins \& J. L. Northern (Eds.), Seminars in speech and language (pp. 111-118). New York: Thieme-Stratton.

Hurst, J. A., Baraitser, M., Auger, E., Graham, F., \& Norell, S. (1990). An extended family with a dominantly inherited speech disorder. Developmental Medicine and Child Neurology, 32, 352-355.

Khan, L., \& Lewis, N. (1986). Khan-Lewis Phonological Analysis. Circle Pines, MN: American Guidance Service.

Lahey, M., \& Edwards, J. (1995). Specific language impairment: Preliminary investigation of factors associated with family history and patterns of language performance. Journal of Speech and Hearing Research, 38, 643-657.

Lai, C. S. L., Fisher, S. E., Hurst, J. A., Vargha-Khadem, F., \& Monaco, P. (2001). A forkhead-domain gene is mutated in a severe speech and language disorder. Nature, 413, 519-523.

Lewis, B. A. (1990). Familial phonological disorders: Four pedigrees. Journal of Speech and Hearing Disorders, 55, 160-170.

Lewis, B. A. (1992). Pedigree analysis of children with phonology disorders. Journal of Learning Disabilities, 25(9), 586-597.

Lewis, B. A., Ekelman, B. L., \& Aram, D. M. (1989). A family study of severe phonological disorders. Journal of Speech and Hearing Research, 32, 713-724.

Lewis, B. A., \& Freebairn, L. (1993). A clinical tool for evaluating the familial basis of speech and language disorders. American Journal of Speech and Language Pathology, 2, 38-43.

Lewis, B. A., Freebairn, L., \& Taylor, H. G. (2000). Follow-up of children with early expressive phonology disorders. Journal of Learning Disabilities, 33, 433-444.

Lewis, B. A., \& Thompson, L. A. (1992). A study of developmental speech and language disorders in twins. Journal of Speech and Hearing Research, 35, 1086-1094.

Milloy, N., \& Summers, L. (1989). Six years on- do claims still hold? Four children reassessed on a procedure to identify developmental articulatory dyspraxia. Child Language Teaching and Therapy, 5, 287-303.

Morley, M. E. (1965). The development and disorders of speech in childhood (2nd ed.). Baltimore: Williams and Wilkins Company.

Morley, M. E. (1957). The development and disorders of speech in childhood. London, England: Livingstone.

Neils, J., \& Aram, D. M. (1986). Family history of children with developmental language disorders. Perceptual and Motor Skills, 63, 655-658.

Newcomer, P. L., \& Hammill, D. D. (1988). Test of Language Development-Primary (2nd ed.) Austin, TX: Pro-Ed.

Ozanne, A. (1997). The search for developmental verbal dyspraxia. In B. Dodd (Ed.), The differential diagnosis and treatment of children with speech disorder (pp. 91-109). London: Whurr Publishers.

Plomin, R., DeFries, J. C., McClearn, G. E., \& Rutter, M. (1997). Behavior Genetics (3rd ed.). New York: W.H. Freeman and Company.

Rice, M. L., Haney, K. R., \& Wexler, K. (1998). Family histories of children with SLI who show extended optional infinitives. Journal of Speech, Language, and Hearing Research, 41, 419-432.

Riley, G. D. (1984). Developmental verbal dyspraxia: A clinical perspective. Australian Journal of Human Communication Disorders, 12, 83-91.

Robbins, J., \& Klee, T. (1987). Clinical assessment of oropharyngeal motor development in young children. Journal of Speech and Hearing Disorders, 52, 271-277.

Saleeby, N. C., Hadjian, S., Martinkosky, S. J., \& Swift, M. R. (1978). Familial verbal dyspraxia: A clinical study. Paper presented at the American Speech-Language-Hearing Association Annual Convention, November, San Francisco, CA.

Semel, E., Wiig, E. H., \& Secord, W. (1987). Clinical Evaluation of Language Fundamentals—Revised. San Antonio, TX: The Psychological Corporation.

Shriberg, L. D., Aram, D. M., \& Kwiatkowski, J. (1997a). Developmental apraxia of speech: I. Descriptive perspectives. Journal of Speech, Language, and Hearing, Research, 40, 273-285. 
Shriberg, L. D., Aram, D. M., \& Kwiatkowski, J. (1997b). Developmental apraxia of speech: II. Toward a diagnostic marker. Journal of Speech, Language, and Hearing, Research, 40, 286-312.

Shriberg, L. D., Austin, D., Lewis, B. A., McSweeny, J. L., \& Wilson, D. L. (1997). The Percentage of Consonants Correct (PCC) metric: Extensions and reliability data. Journal of Speech, Language, and Hearing, Research, 40, 708-722.

Shriberg, L. D., \& Kwiatkowski, J. (1994). Developmental phonological disorders I: A clinical profile. Journal of Speech and Hearing Research, 37, 1100-1126.

Shriberg, L. D., Tomblin, J. B., \& McSweeny, J. L. (1999). Prevalence of speech delay in 6-year-old children and comorbidity with language impairment. Journal of Speech, Language, and Hearing Research, 42, 1461-1481.

Spitz, R. V., Tallal, P., Flax, J., \& Benasich, A. A. (1997). Look who's talking: A prospective study of familial transmission of language impairments. Journal of Speech and Hearing Research, 40, 990-1001.

Stackhouse, J. (1992). Developmental verbal dyspraxia I: A review and critique. European Journal of Disorders of Communication, 27, 19-34.

Tallal, P., Ross, P., \& Curtiss, S. (1989). Familial aggregation in specific language impairment. Journal of Speech and Hearing Research, 54, 167-173.

Thoonen, G., Maassen, B., Gabreels, F., Schreuder, R., \& de Swart, B. (1997). Towards a standardised assessment procedure for developmental apraxia of speech. European Journal of Disorders of Communication, 32, 37-60.

Tomblin, J. B. (1989). Familial concentration of developmental language impairment. Journal of Speech and Hearing Disorders, 54, 287-295.

Tomblin, J. B., \& Buckwalter, P. (1998). Heritability of poor language achievement among twins. Journal of Speech, Language, and Hearing Research, 41(1), 188-199.

Tomblin, J. B., Records, N. L., Buckwalter, P., Zhang, X., Smith, E., \& O’Brien, M. (1997). Prevalence of specific language impairment in kindergarten children. Journal of Speech and Hearing Research, 40, 1245-1260.

Vargha-Khadem, F., Watkins, K., Alcock, K., Fletcher, P., \& Passingham, R. (1995). Praxic and nonverbal cognitive deficits in a large family with a genetically transmitted speech and language disorder. Proceedings of the National Academy of Sciences of the United States of America, 92(3), 930-933.

Velleman, S. L., \& Strand, K. (1994). Developmental verbal dyspraxia. In J. E. Bernthal \& N. W. Bankson (Eds.), Child phonology: Characteristics, assessment, and intervention with special populations (pp. 110139). New York: Theime.

Watkins, K. E., Dronkers, N. F., \& Vargha-Khadem, F. (2002). Behavioural analysis of an inherited speech and language disorder: Comparison with acquired aphasia. Brain, 125, 452-464.

Watkins, K. E., Vargha-Khadem, F., Ashburner, J., Passingham, R. E., Connelly, A., Friston, K. J., Frackowiak, R. S. J., Mishkin, M., \& Gadian, D. G. (2002). MRI analysis of an inherited speech and language disorder: Structural brain abnormalities. Brain, 125(3), 465-478.

Wechsler, D. (1989). Wechsler Preschool and Primary Scale of Intelligence-Revised. San Antonio, TX: The Psychological Corporation.

Wechsler, D. (1991). Wechsler Intelligence Scale for Children-Third edition. San Antonio, TX: The Psychological Corporation. 